\title{
Nursing management, religion and spirituality: a bibliometric review, a research agenda and implications for practice
}

JOHN G. CULLEN вA (Hons), MA, Mlis, Dip Man, PgDHe, PhD

Senior Lecturer, School of Business, Maynooth University, Maynooth, Co. Kildare, Ireland

Correspondence

John G. Cullen

School of Business

Maynooth University

Maynooth

Co. Kildare

Ireland

E-mail: john.g.cullen@nuim.ie
CULLEN J.G. (2016) Journal of Nursing Management 24, 291-299.

Nursing management, religion and spirituality: a bibliometric review, a research agenda and implications for practice

Aims This article aims to contribute to the growing field of spirituality and nursing management by analysing bibliographic data on peer-reviewed research in the field.

Background Articles on spirituality and nursing management often claim that these fields have grown over the past two decades. This article gathers empirical evidence to test these claims.

Evaluation Bibliometric data on peer-reviewed research articles on nursing, nursing management, spirituality and religion in the Social Sciences Citation Index were analysed to ascertain general trends in publication and citation.

Key issues The data support claims that research activity and interest in both spirituality and religion in the field of nursing have grown steeply over recent years, and continue to accelerate.

Conclusions The research identified spirituality as a beneficial variable in management, training and/or care scenarios. Critical studies of nursing management spiritual initiatives could add considerably to the growing body of research and theory in this field.

Implications for nursing management It is essential that nurse managers be equipped to foster not only a broader understanding of the variety of faith traditions found in a multi-cultural society, but also to develop an understanding of the ways in which individuals engage in spiritual practice outside traditional religious settings.

Keywords: bibliometrics, nurse managers, nurses, religion, spirituality

Accepted for publication: 15 September 2015

\section{Aims}

This article aims to contribute to the growing field of spirituality and nursing management by collecting, presenting and analysing bibliographic data on peerreviewed research in the field, and to compare it with similar work undertaken on religion and nursing management. In doing so, it aims to clarify the nature of theoretical growth in these related areas, and to identify lacunae that can be addressed by further research.
The paper also aims to identify implications for nursing management practice arising from the bibliometric review.

\section{Background}

Several authors claim that interest in spirituality has grown in the practical and theoretical communities of nursing management over the past two decades (Reimer-Kirkham et al. 2012, Timmins \& McSherry 
2012). Similarly, business management scholars have reported that the field of management in the corporate sector has been gradually 'spiritualised' since the 1990s (Ackers \& Preston 1997). This 'spiritualisation' has often been facilitated by human resource development and management training practices (Cullen 2008), which borrow heavily from 'new age' spiritual beliefs (Heelas 1996, Bell \& Taylor 2004, Cullen 2009) that emphasise quests for personal growth and flourishing as opposed to observing the rules of an established faith tradition or religious organisation. Following two decades of such apparent growth (which was evidenced by events such as the establishment of a 'Management, Spirituality \& Religion' special interest group at the Academy of Management in the late 1990s and the Journal of Management, Spirituality \& Religion was first published in 2004), Oswick (2009) undertook a bibliometric analysis of peer-reviewed research literature on the topic in order to present an empirically based overview of the growth that the field had undergone in order to demonstrate how the newly emerging sub-field was developing in terms of praxis and scholarship. This article utilises and adapts Oswick's research methodology in order to do the same for the topics of spirituality and religion in the context of nursing management.

Before moving on to explain the technical elements of Oswick's analysis, it is important to outline why 'religion' and 'spirituality' are reviewed separately in this article. Often, these terms are often applied interchangeably, which can lead to confusion. It is sometimes presumed that people who self-identify as religious, consider themselves to be spiritual. On the other hand, many people who claim to be spiritual are often at pains to point out that they are not religious. However, as Vitell points out, 'spirituality and religiosity can be strongly linked even if they are not, strictly speaking, exactly the same' (2009, p. 156). When religion (or religiosity) is considered as a variable in empirical studies it is often equated with 'understanding, committing to and following a set of religious doctrines or principles' (Bloodgood et al. 2008). Spirituality, on the other hand, is often associated with the mindset of an individual who is engaged with a quest for personal enlightenment and/or fulfilment and does not follow one (or any) set of religious doctrines, and as such is unlikely to identify as adhering to or belonging to one particular faith tradition (Heelas 1996). Heelas and Woodhead (2005) locate spirituality in the realm of the immanent, and religion with the transcendent:

\begin{abstract}
'Most notably the term 'spirituality' is often used to express commitment to a deep truth that is to be found within what belongs to this world. And the term 'religion' is used to express commitment to a higher truth that is 'out there', lying beyond what this world has to offer, and exclusively related to specific externals (scriptures, dogmas, rituals and so on)'
\end{abstract}

(p. 6).

However, it is important to consider two important problems with defining religion in terms of dogma and doctrine, and spirituality as a liberated search for personal fulfilment that involves drawing on, but not committing to, established religious traditions and organisations. The first problem is that many groups that one might identify as religious are often nondogmatic. Timmins and McSherry (2012), for example, point out that Paganism has come to be recognised as a religion in its own right, yet Butler (2011) highlights that there is a huge degree of fluidity amongst individual Pagans (regardless of their membership of specific sub-groups or Covens) as to how they practice their faith. Similarly, although Roman Catholicism has often been accused of emphasising the centrality of infallible Papal rulings on matters of personal morality, recent research has demonstrated that followers are more likely to apply their own discretion to these (Inglis 2007): 'Beliefs and practices which, although derived from the church's teachings, are filtered through personal interpretations that have ceased to be under clerical control' (Aldridge 2013, p. 203).

The second problem is that religious people are often misunderstood as uncritical consumers of dogma, and are sometimes unfairly accused of docility in their acceptance of centrally administered doctrine (Bell 2008). William James' The Varieties of Religious Experience (1906, [1902]) problematises the variable of 'religion' within realist social science, by demonstrating that most individuals do not retain a fixed religious (or non-religious) attitude throughout their lives. Instead, people tend to have varieties of experiences within their own faith position, which vacillates across the individual's lifespan. Although organised religions may be accused of drafting and propagating dogma, the way that individuals experience this varies depending on the circumstances in which they find themselves. The fact that an individual's religious identity is subject to such mutability makes it difficult to convey 'religion' as a relatively stable variable such as 'gender' or 'race'. 


\section{Evaluation}

Oswick (2009) conducted a bibliometric analysis of published material on the topic of workplace spirituality to develop 'a longitudinal aggregation of published material to establish emergent trends' (p. 16). A considerable element of this project was the analysis of publication citation rates on workplace spirituality and business and management in the Social Sciences Citation Index (SSCI). The SSCI is considered to be the highest quality indexer and rater of social science periodicals that has evolved since the 1950s (Wang et al. 2012).

Over the week of 19-23 January 2015, the search term 'Spiritual*' was entered as a topic search in the SSCI for the years 1995-2014. The wildcard character '*' was entered to 'capture' variations on terms related to spirituality, such as: spirit; spiritualised; spiritual, or; spiritually. Topic search was used as it is the most comprehensive field for capturing all mentions of the search term in the title, abstract and keyword of the searched peer-reviewed articles. This search returned 14725 hits and the category of 'nursing' contained the fourth highest number of results $(n=1382)$. Of these 1146 were for articles in peer-reviewed periodicals. There was a steep acceleration of peer-reviewed article publications and citations which contained 'spiritual*' in the title, abstract or keyword over the 20 years from 1995 to 2014 (28 items were published in the years prior to 1995 and 10 of these were published in 1994; 50 items were cited prior to 1995 and 21 of these were cited in 1994).

The search term 'Religio*' was entered as a topic search to capture variations on spellings of religious, religion and religiosity. Results for the search term 'Religio*' as the topic search demonstrate smaller numbers of publications and citations, but a similar growth rate. A larger number of hits for 'religio*' was returned than for 'spiritual*' (60 888 as opposed to 14725 ), but fewer results $(n=916)$ were included in the 'nursing' category and 809 of these were for peer-reviewed articles. Evidence of the growth rate for both fields can be found in the fact that $45.5 \%$ of publications were returned for the last 4 years of the 'Spiritual*' results, and $48 \%$ for the 'Religio*' results. 322 article publications were returned that contained both spiritual* and religio* as a topic search in the field of nursing.

These data on peer-reviewed publications and citations demonstrate that research interest in spirituality and religion in the field of nursing has increased over the past 20 years. It also establishes that this interest has accelerated and continues to grow, particularly in relation to spirituality. As this article is concerned with nursing management, religion AND spirituality, the analysis then focused on cross-referencing the 'spiritual*' and 'religio*' search terms with 'manag*' (to represent managers, managing, managerial and management). Although the results for both of these terms demonstrated that the literature has experienced the same growth rate as for nursing, spirituality and religion in general, the literature in nursing management, spirituality and religion is smaller. The 'spiritual*' and 'manag*' search captured 1104 hits, of which 982 were peer-reviewed articles. 180 of these were found in the nursing sub-category and were isolated for further analysis. The 'religio*' and 'manag*' search captured 1761 hits, of which 1620 were peerreviewed articles. 107 of these were found in the nursing sub-category and were also isolated for review.

The abstracts for all articles were examined and it was decided that the following criteria would be applied to the process of reducing the literature studied to that appropriate to the field of investigation. Papers that discussed 'management' as a clinical practice issue (such as pain management or hypertension management) were excluded from the review. The application of this criterion resulted in the removal of 237 records which left a total of 50 articles for review. References to management as a practice and a field of study that involved managing and administering resources and staff were included. Three duplicate articles were removed from this group, which meant that 47 articles were selected for analysis. A list of these articles has been included as Appendix S1 to this article. The process by which the articles were selected for analysis is outlined in Figure 1.

An MS-Access database was created and information in the following fields was entered to assist the analysis of the bibliographic data:

- Source of publication (Journal titles).

- Type of article (e.g. Conceptual/theoretical, Opinion/editorial, review, empirical).

- Geographical location of the study reported.

- General type of methodological approach used (i.e. qualitative, quantitative, mixed methods).

- Specific research methods applied.

- Unit of analysis (nurse managers, administrators or executives; nurses; patients).

- Was a specific faith group identified and if so what faith group(s)?

- Beneficiaries of the outputs (patients, families, nurses and managers). 


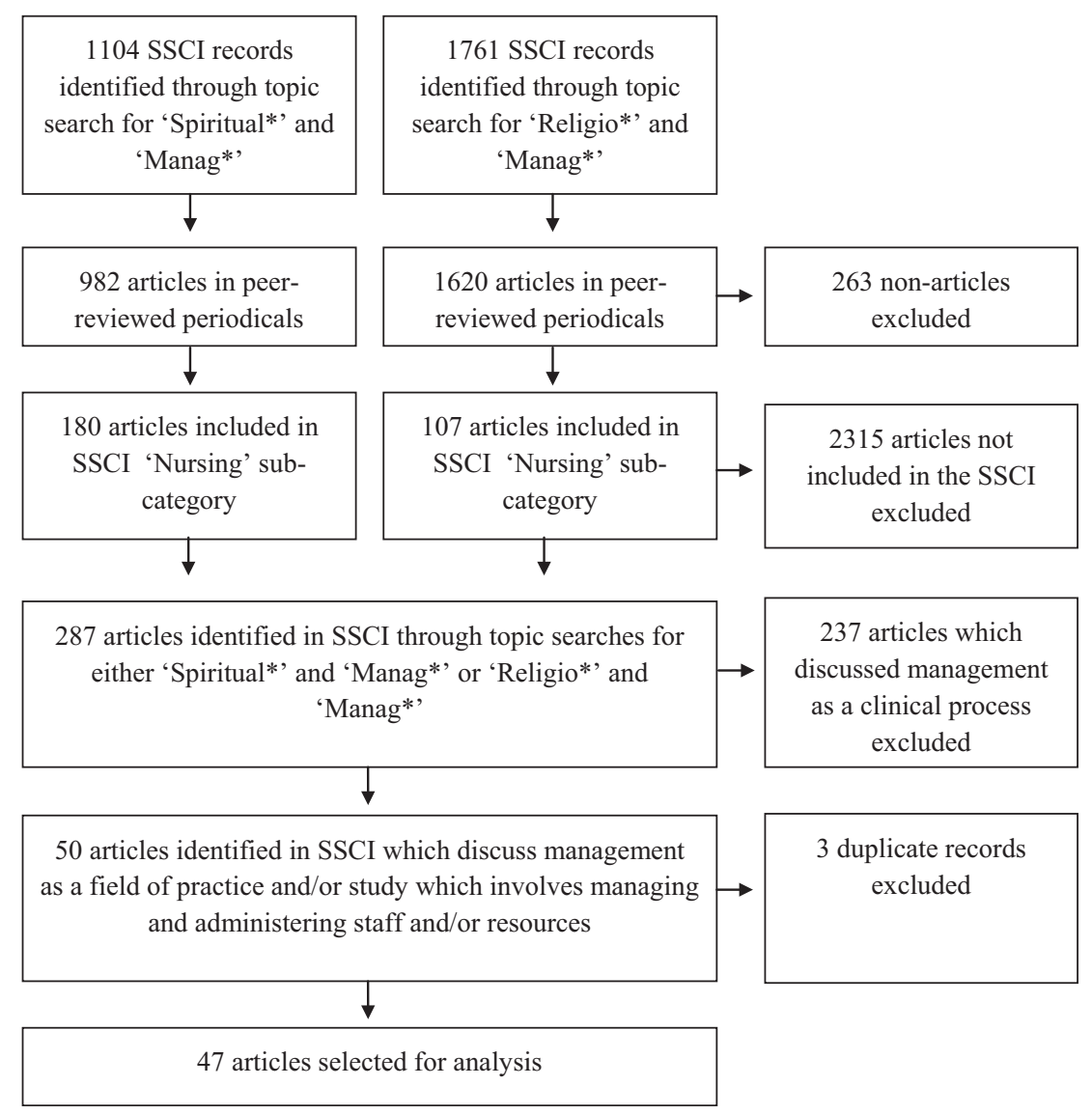

Figure 1

PRISMA flow diagram of selection of articles for analysis.

A noticeable element in the initial review of all articles selected for primary review was that spirituality and religion were given differing weightings in each article. In some, they were a central concern to the research undertaken, and in others they were mentioned in passing and often in ways that did not significantly influence the main research question being investigated. Because of this, a 'weighting' system was applied to the final set of 47 articles. Articles in which spirituality and/or religion were central to the work reported in the article were termed level 1 articles. Articles in which spirituality and/or religion were important to the work reported in the article were designated as level 2 articles. Articles in which spirituality and/or religion were considered in the article, but were not central to the key question were labelled level 3 articles. Finally, articles that mentioned spirituality and/or religion as an output in a passing manner (usually as a factor to be considered in practice or in future research alongside other variables), were designated as level 4 articles. Of 47 articles selected for analysis, most $(n=24,51.1 \%)$ proved to be level 1 articles. Seven $(14.9 \%)$ were categorised as level $2 ; 11$ $(23.4 \%)$ as level 3 ; and $5(10.6 \%)$ as level 4 . There was equal distribution of spiritually and religiously oriented articles. Twenty two $(46.8 \%)$ were classified as religious and $20(46.6 \%)$ were spiritually focused. The remaining five $(10.6 \%)$ were concerned with both spirituality and religion.

Although spirituality, nursing and management was treated as a topic in a wide variety of nursing journals, it is clear from Table 1 that the most substantial level of coverage was afforded by the Journal of Nursing Management.

The vast majority of the 47 articles were empirical studies $(n=40 ; 85.1 \%)$. Three were conceptual or theoretical, two were commentaries or opinion pieces and two were review articles. Thirty six $(76.6 \%)$ of the articles mentioned the geographical location where the research was undertaken, and with the exception of African countries, all continents were represented. Most research was undertaken in the USA $(n=8$, $17 \%)$ and $\operatorname{Iran}(n=8,17 \%)$. There was also an equal distribution of research approaches used. Twenty one 
Table 1

Journal sources of publications on the topic of nursing, management and spirituality

\begin{tabular}{lcr}
\hline Journal Title & Frequency & Percent \\
\hline Journal of Nursing Management & 16 & 34.0 \\
Journal of Advanced Nursing & 6 & 12.8 \\
International Nursing Review & 4 & 8.5 \\
Oncology Nursing Forum & 3 & 6.4 \\
International Journal of Nursing Practice & 2 & 4.3 \\
Aquichan & 1 & 2.1 \\
Australian Journal of Advanced Nursing & 1 & 2.1 \\
Cancer Nursing & 1 & 2.1 \\
International Journal of Nursing Studies & 1 & 2.1 \\
Journal of Continuing Education in Nursing & 1 & 2.1 \\
Journal of Gerontological Nursing & 1 & 2.1 \\
Journal of Nursing Administration & 1 & 2.1 \\
Journal of Nursing Scholarship & 1 & 2.1 \\
Journal of Psychiatric and Mental Health & 1 & 2.1 \\
Nursing & & \\
Nursing \& Health Sciences & 1 & 2.1 \\
Nursing Economics & 1 & 2.1 \\
Nursing Ethics & 1 & 2.1 \\
Nursing History Review & 1 & 2.1 \\
Nursing Science Quarterly & 1 & 2.1 \\
Revista da Escola de Enfermagem da USP & 1 & 2.1 \\
Workplace Health \& Safety & 1 & 2.1 \\
Total & 47 & 100.0 \\
\hline
\end{tabular}

(44.7\%) used qualitative approaches and 20 (42.6\%) used quantitative approaches. Four articles were either entirely conceptual or did not clearly state the research approach they applied, and one used a mixed methodology. The specific methods applied in the 47 articles are outlined in Table 2 .

The evidence collected in this article demonstrates that research interest in the topic is increasing. During the 5 years from 1995 to 2000 only four articles were published and this halved between 2001 and 2005 to two. Between 2006 and 201013 articles were published. Twenty nine articles were published between 2011 and 2014. As outlined in Figure 2 almost 60\% of the articles on nursing management, spirituality and religion were published in the most recent 4 years of the timeframe under review.

Interestingly, although nurse managers were researched in many studies, the primary subjects of studies were the nurses who were being managed $(n=20,42.6 \%)$, followed by patients $(n=7,14.9 \%)$. A full breakdown of the subjects of each study is provided in Table 3.

No specific religious groups were mentioned in 38 $(80.8 \%)$ of the articles. Roman Catholics were the subject of three $(6.4 \%)$ studies; Buddhists and Muslims featured in two $(4.3 \%)$ each. Single studies were concerned with Jews or Greek Orthodox Christians. It is perhaps interesting to note that the beneficiaries of the findings of the research were mainly stated as
Table 2

Methods used to research nursing management, religion and spirituality

\begin{tabular}{lcc}
\hline Method & Frequency & Percent \\
\hline Questionnaire & 10 & 4.7 \\
Literature review & 4 & 1.9 \\
Semi-structured interviews & 4 & 1.9 \\
Historical study & 3 & 1.4 \\
N/A & 3 & 1.4 \\
Cross-sectional survey & 2 & 0.9 \\
Integrative review & 2 & 0.9 \\
Interviews & 2 & 0.9 \\
Open interviews & 2 & 0.9 \\
Application of a model from the sociology of & 1 & 0.5 \\
religion & & \\
Baseline data collection & 1 & 0.5 \\
Case study & 1 & 0.5 \\
Concept analysis & 1 & 0.5 \\
Content analysis & 1 & 0.5 \\
Ethnographic & 1 & 0.5 \\
Experimental study & 1 & 0.5 \\
Exploratory study, questionnaire, multi-level & 1 & 0.5 \\
study & & \\
Focus groups, semi-structured interviews & 1 & 0.5 \\
Grounded theory & 1 & 0.5 \\
Hermeneutics & 1 & 0.5 \\
Meta-analysis & 1 & 0.5 \\
Mixed methods & 1 & 0.5 \\
Quasi-experimental & 1 & 0.5 \\
Two-question algorithm & 1 & 0.5 \\
Total & 47 & 22.1 \\
\hline
\end{tabular}

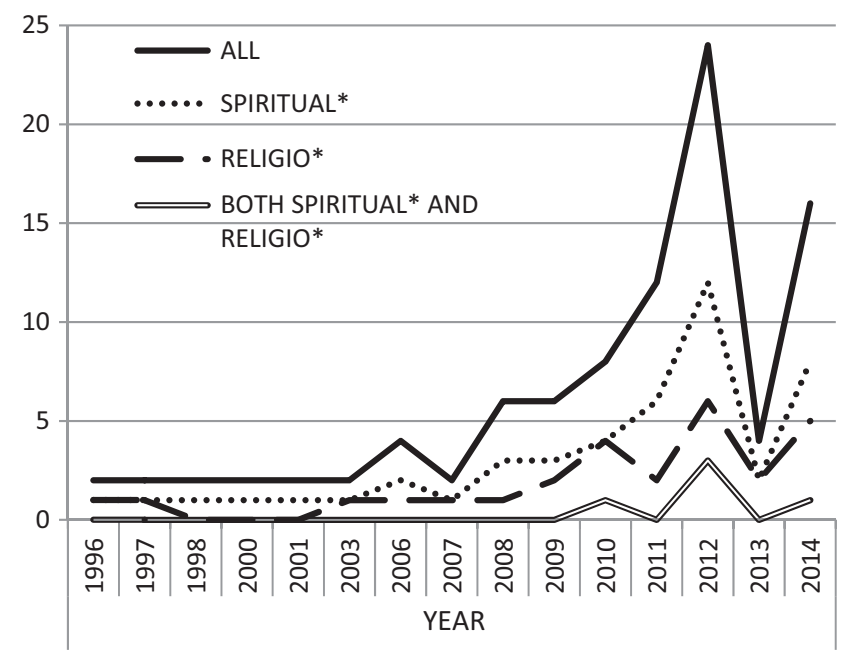

Figure 2

Growth rates in articles analysed (1995-2014).

nurses and patients (see Table 4) rather than members of any particular faith community.

The research needs arising from this research called for work that addressed the ways in which nurse managers could encourage the development of spirituality in ways that could practically improve the lived 
Table 3

Unit of analysis

\begin{tabular}{lrr}
\hline Unit & Frequency & Percent \\
\hline Nurses & 20 & 42.6 \\
Patients & 7 & 14.9 \\
Nurse managers & 5 & 10.6 \\
Managers & 2 & 4.3 \\
Nurse managers, patients & 2 & 4.3 \\
Families of patients & 1 & 2.1 \\
Health-care staff & 1 & 2.1 \\
Historical study & 1 & 2.1 \\
Literature & 1 & 2.1 \\
Nurse administrators & 1 & 2.1 \\
Nurse managers, nurses & 1 & 2.1 \\
Nurses aides & 1 & 2.1 \\
Nurses, chaplains & 1 & 2.1 \\
Nurses, doctors, patients & 1 & 2.1 \\
Nursing executives & 1 & 2.1 \\
Student nurses & 1 & 2.1 \\
Total & 47 & 100.0 \\
\hline
\end{tabular}

Table 4

Beneficiaries of nursing management, religion and spirituality research

\begin{tabular}{lcc}
\hline Beneficiaries of outcomes & Frequency & Percent \\
\hline Nurses & 15 & 31.9 \\
Patients & 13 & 27.7 \\
Nurse managers & 7 & 14.9 \\
Nurse managers, nurses & 2 & 4.3 \\
Nurses, patients & 2 & 4.3 \\
Patients and families & 2 & 4.3 \\
Health-care staff & 1 & 2.1 \\
Nurse administrators & 1 & 2.1 \\
Nurse managers, patients & 1 & 2.1 \\
Nurses aides & 1 & 2.1 \\
Nurses, doctors, patients & 1 & 2.1 \\
Student nurses & 1 & 2.1 \\
Total & 47 & 100.0 \\
\hline
\end{tabular}

experiences of the nurses they managed, and the patients for whose care they were responsible.

\section{Key issues}

The empirical data support assertions that the import afforded to spirituality and religion in nursing management research (and particularly religion) has grown steeply over the past two decades, and continues to accelerate. The articles studied were evenly split between studying nursing management in relation to both religion and spirituality, and in $10 \%$ of cases, both these areas. The Journal of Nursing Management is clearly the lead publisher of empirical and conceptual research in the field. The main focus of the research tends to be on nurses, patients and nurse managers as both units of analysis, and beneficiaries of the research.

\section{Conclusions}

As this is the first bibliometric analysis of spirituality and religion in the context of nursing management it is important to highlight the limitations of this approach. Spirituality and religion are often researched from sociological, psychological and theological perspectives within the realm of the social and human sciences. As research fields they are often notoriously 'difficult-to-access' areas of investigation. Individual patients, nurses and managers may find it difficult to articulate their spiritual or religious beliefs, which in turn can lead to different understandings about the unit of analysis under investigation. As mentioned earlier William James's (1906 [1902]) assertion that individuals engage with religion variously throughout their life is an important factor to be considered when studying religious and spiritual experience. Systematic reviews and meta-analyses tend to review large amounts of empirical research, and this process does not always lend itself to accurately capturing the more nuanced approaches to understanding spiritual and religious identity in context. One researcher's understanding or experience of religion, may differ radically from another. When these dissimilarities were encountered in this paper it was necessary to segregate them into four different levels. Other approaches for engaging this problem might be considered in future research.

Definitional problems with the terms 'religion' and/ or 'spirituality' are also limitations on the types of studies that are undertaken. For example, non-theistic experiences with the spiritual (such as in Buddhism) appear to be very different from those in Abrahamic monotheistic faiths.

A major methodological limitation is that this study chose to focus on articles that were published in an English language medium. As mentioned earlier in this research, most continents were represented in the fieldwork undertaken for this project which demonstrates the strong likelihood that the body of research on spirituality and religion in the field of nursing management is of global interest. A study that could analyse bibliometric data from an international, multilingual dataset would create an even more comprehensive portrait of spirituality and religion in nursing management practice.

The research analysed tends to focus on spirituality and/or religion as a central variable, and rarely extends into broader theoretical discussions which have emerged in relation to workplace spirituality. There are distinct opportunities for extending the 
understanding of the role of spirituality in nursing management by engaging with contemporary debates in the sociology of workplace spirituality.

The research reviewed for this article exclusively focused on spirituality as a beneficial variable in management, training and/or care scenarios. None of the 47 articles analysed considered the possible negative outcomes that might arise from encouraging workplace spirituality. Carrette and King (2005) have demonstrated how the introduction of spirituality to the workplace may corrode the religious/spiritual by applying it in a context that is not appropriate, but additionally may also exploit working nurses and managers. For example, there has been an increase in the amount of literature that explores the concept of 'vocation' or 'calling' in the contemporary workplace (Heyes 2005, Cullen 2013, Berkelaar \& Buzzanell 2015). Heyes (2005) demonstrated that thinking of nursing as a vocation has provided a rationale for denying appropriate levels of payment to people who are driven to fulfiling a calling of care to vulnerable and sick people. Although vocations and callings are no longer exclusively religious concepts, they have emerged from a religious understanding of occupational choice (Weber 1930/1992, Hall \& Chandler 2005). If the spiritual aspect of one's calling as a nurse or a nurse manager is deployed as a means to cut fair levels of remuneration, then this represents that the introduction of spirituality into a workplace is not entirely an 'innocent' activity. Management researchers of spirituality and religion in corporate settings have warned how the positive spiritual work experiences of managers, employees and clients are at risk of being appropriated by capitalist agendas (Bell \& Taylor 2004, Carrette \& King 2005, Oswick 2009). Similarly, there is a dearth of research on spirituality and religion by nursing management researchers that investigates how spirituality might be 'deployed' as an organisational resource that satisfies the needs of certain powerful groups at the expense of others (Cullen 2011a). As such, the introduction of more critical studies of nursing management spiritual initiatives would be a welcome addition to the growing body of research in this field. Such research should in no way denigrate or deny the importance of a patient's spiritual and/or religious identity in aiding recovery or accepting their health condition.

\section{Implications for nursing management}

Many papers called for more resources to be made available to nurse managers, nurses and students to understand the spiritual dimension of care. Although some papers called for greater levels of understanding of various faith traditions and their expectations in relation to the dignity of the patient, much more emphasis is placed in the articles analysed on the development of an appropriate response to the secularisation of society and public institutions (Taylor 2007). Many countries are becoming more cosmopolitan and multi-cultural, or are undergoing a secularising process that reduces the possibility of enabling the spiritual dimension of health care (especially if nurses do not identify as religious or spiritual themselves). Greater levels of engagement with 'spiritual care providers' was recommended, particularly in end-of-life care settings.

Perhaps the key finding in this research is that interest in the area of nursing management and spirituality has mirrored the growth of the broader field of management and spirituality research and theory development. This growth is representative of a broader societal turn towards personal spiritual inquiry and development, as opposed to accepting and engaging with established religious doctrine and traditions (Heelas \& Woodhead 2005). Given the importance of spirituality to the work that nurses do in health-care settings, it is vital that nurse managers be equipped to develop an understanding of this socio-religious change.

'This means that individuals in spiritualised societies have a tendency to look less to established religious frameworks, such as churches, for guidance on how to behave, cosmological information on how they will be judged or rewarded for appropriate behaviour in this life or the next, forgiveness for listed transgressions, or solace during times of distress. Rather, more energy is placed on attempting to understand the meaning of one's existence in the context of life experiences, leveraging one's personal learning and investigation, and adopting a syncretic approach to acquiring spiritual wisdom from a number of diverse and often unrelated sources'

$$
\text { (Cullen 2011b, p. 590). }
$$

This has many implications for the nursing manager. In the past, religious diversity was respected through the provision of sensitivity awareness as to what was sacred to particular faith traditions and cultures. The development of a greater level of social 'spiritualisation' would mean that an extension of this awareness is required. Nurse managers need to be introduced to the many ways in which religious experience has 
become more subjective and individualised as part of the recent expressive 'turn' (Heelas 1996). For example, Roman Catholicism is often represented as having a monolithic set of articles of faith and a specific set of practices. Recent research on the religious identity and experience of Roman Catholics, however, has demonstrated that, while these sacramentals have remained, many Catholics have customised these practices in order to pursue a more reflexive form of their spirituality (Inglis 2007, Fuller 2008, Cullen 2011b). In other words, nurses and nurse managers could benefit from developing a deeper understanding of not only what their patients and their families believe, but also how they believe and how these beliefs are changing in contemporary society.

The sociology of religion has demonstrated the many ways in which spiritual experience has changed in developed nations since the late 1960s. Particular attention has been paid to how this change has impacted on the experiences of employees and managers in a variety of organisational types. Nursing management has engaged with religion and spirituality as part of this overall project. Just as spirituality and management has carved out its own niche in the field of management studies, there is a rich opportunity for developing a similar field of investigation that is specific to the nurse management context.

\section{Source of funding}

This research undertaken for this article was not completed with the aid of commercial or non-commercial funding or research support.

\section{References}

Ackers P. \& Preston D. (1997) Born again?: the ethics and efficacy of the conversion experience in contemporary management development. Journal of Management Studies 34 (5), 677-701.

Aldridge A. (2013) Religion in the Contemporary World: A Sociological Introduction. Cambridge, Polity.

Bell E. (2008) Towards a critical spirituality of organization. Culture and Organization 14 (3), 293-307.

Bell E. \& Taylor S. (2004) 'From outward bound to inward bound': the prophetic voices and discursive practices of spiritual management development. Human Relations 57 (4), 439-466.

Berkelaar B.L. \& Buzzanell P.M. (2015) Bait and switch or double-edged sword? The (sometimes) failed promises of calling. Human Relations 68 (1), 157-178.

Bloodgood J.M., Turnley W.H. \& Mudrack P. (2008) The influence of ethics instruction, religiosity, and intelligence on cheating behavior. Journal of Business Ethics 82 (3), 557571.

Butler J. (2011) Irish neo-paganism: world-view and identity. In Ireland's New Religious Movements (O. Cosgrove, L. Cox \& P. Mulholland eds), pp. 211-230. Cambridge Scholars, Newcastle-Upon-Tyne.

Carrette J.R. \& King R. (2005) Selling Spirituality: The Silent Takeover of Religion. Routledge, London; New York.

Cullen J.G. (2008) Self, soul and management learning: constructing the genre of the spiritualized manager. Journal of Management, Spirituality \& Religion 5 (3), 264-292.

Cullen J.G. (2009) How to sell your soul and still get into Heaven: Steven Covey's epiphany-inducing technology of effective selfhood. Human Relations 62 (8), 1231-1254.

Cullen J.G. (2011a) Researching workplace spiritualization through auto/ethnography. Journal of Management, Spirituality \& Religion 8 (2), 143-164.

Cullen J.G. (2011b) Spirituality, work and Irish society. In Irish Business and Society: Governing, Participating and Transforming in the 21st Century (J. Hogan, P.F. Donnelly \& B.K. O'Rourke eds), pp. 589-603. Macmillan, Dublin.

Cullen J.G. (2013) Vocational ideation and management career development. Journal of Management Development 32 (9), 932-944.

Fuller W. (2008) 'But at least I'm aware I'm ignoring it!': reflexive Catholicism in Ireland. In Belongings: Shaping Identity in Modern Ireland (M.P. Corcoran \& P. Share eds), pp. 167180. Institute of Public Administration, Dublin.

Hall D.T. \& Chandler D.E. (2005) Psychological success: when the career is a calling. Journal of Organizational Behavior 26 (2), 155-176.

Heelas P. (1996) The New Age Movement: The Celebration of the Self and the Sacralization of Modernity. Blackwell, Oxford; Cambridge, MA.

Heelas P. \& Woodhead L. (2005) The Spiritual Revolution: Why Religion is Giving Way to Spirituality. Blackwell, Malden, MA.

Heyes A. (2005) The economics of vocation or 'why is a badly paid nurse a good nurse'? Journal of Health Economics 24 (3), 561-569.

Inglis T. (2007) Catholic identity in contemporary Ireland: belief and belonging to tradition. Journal of Contemporary Religion 22 (2), 205-220.

James W. (1906 [1902]) The Varieties of Religious Experience: A Study in Human Nature. Longman, London.

Oswick C. (2009) Burgeoning workplace spirituality? A textual analysis of momentum and directions. Journal of Management, Spirituality \& Religion 6 (1), 15-25.

Reimer-Kirkham S., Pesut B., Sawatzky R., Cochrane M. \& Redmond A. (2012) Discourses of spirituality and leadership in nursing: a mixed methods analysis. Journal of Nursing Management 20 (8), 1029-1038.

Taylor C. (2007) A Secular Age. Belknap, Cambridge, MA; London.

Timmins F. \& McSherry W. (2012) Spirituality: the Holy Grail of contemporary nursing practice. Journal of Nursing Management 20 (8), 951-957.

Vitell S. (2009) The role of religiosity in business and consumer ethics: A review of the literature. Journal of Business Ethics 90 (Supplement 2), 155-167. 
Wang G.G., Gilley J.W. \& Sun J.Y. (2012) The 'science of HRD research': reshaping HRD research through scientometrics. Human Resource Development Review 11 (4), 500-520.

Weber M. (1930/1992) The Protestant Ethic and the Spirit of Capitalism. Routledge, London; New York.

\section{Supporting information}

Additional Supporting Information may be found in the online version of this article:

Appendix S1. Overview of articles analysed. 